\title{
Clinical Characterization of Post-parathyroidectomy Patients with Primary Hyperparathyroidism and the Concordance of Preoperative Localization Imaging with Histopathology at a Tertiary Hospital in Manila, Philippines
}

\author{
Danica Francisco, Elizabeth Paz-Pacheco, Perie Adorable-Wagan
}

Section of Endocrinology, Diabetes and Metabolism, Department of Medicine, The Medical City, Pasig City, Philippines

\begin{abstract}
Background. Philippine studies on primary hyperparathyroidism (PHPT) and preoperative localization are scarce, making improvements on detection and recognition particularly difficult.

Objective. Describe the clinical profile of post-parathyroidectomy PHPT patients at The Medical City (TMC) and assess localization rates and concordance of neck ultrasound (UTZ) and 99mTc-sestamibi scan (MIBI) with surgical histopathologic findings.

Methodology. Retrospective chart review of PHPT Filipino patients who underwent parathyroidectomy at The Medical City from January 2004 to August 2018. Clinical profile and presentations were described and compared with international data. Imaging results were compared with surgical histopathology findings and the level of agreement was determined.

Results. Thirty-five patients were analyzed with female predominance (63\%) and an average age of 53 years. Our population had more overt manifestations including skeletal abnormalities (51\%), renal calculi (49\%) and musculoskeletal symptoms (43\%) prior to surgery compared to western countries, where symptoms were noted in less than $20 \%$. $\mathrm{MIBI}$ had higher rates of detection than UTZ $(80 \%$ versus $58 \%)$ but had similar localization rates $(96.4 \%$ versus $94 \%)$. When performed together, given a positive result from either test, a much higher yield (93.8\%) was observed. The level of agreement between MIBI and surgery was $72.5 \%(\mathrm{k}=0.54)$ while UTZ and surgery was $54.1 \%(\mathrm{~K}=0.38)$.

Conclusion. Our Filipino subjects had predominantly overt symptomatic hyperparathyroidism upon diagnosis prior to surgery as opposed to more asymptomatic surgical patients in western countries. Combining UTZ and MIBI is a more successful preoperative localization approach in our setting than performing either imaging alone, especially in patients with nodular goiter.
\end{abstract}

Key words: primary hyperparathyroidism, parathyroidectomy, parathyroid localization

\section{INTRODUCTION}

Primary hyperparathyroidism is a disorder characterized by excessive secretion of parathyroid hormone (PTH) due to one or more hyperactive parathyroid glands, most commonly caused by a parathyroid adenoma. In recent years, the usual presentation in the United States, Canada and Germany is asymptomatic PHPT diagnosed through biochemical tests which are routinely done in these countries. ${ }^{1}$ With the dawn of automated serum calcium measurements in the 1970s, the incidence of hyperparathyroidism increased significantly without relying on the presentation of severe sequelae of the disease, such as osteitis fibrosa cystica or nephrolithiasis, for diagnosis.-4 Because of this regular screening process, the disease is detected early in its course and the opportunity for early intervention, if needed, is presented before the onset of overt symptoms and complications.
Consequently, approximately $20 \%$ of patients exhibit overt symptoms and complications at diagnosis and considered for surgery. ${ }^{5}$ Locally, there is a paucity of studies on patient characteristics and the present state of this disease in our population, limiting discovery of areas for improvement in recognition and diagnosis.

Currently, surgery remains the only curative therapy, with bilateral neck exploration as the gold standard surgical approach yielding a 95\% cure rate. ${ }^{6,7}$ Precise preoperative localization has made it possible to implement more focused and minimally invasive surgeries with high success rates. Minimally invasive parathyroidectomy was found to be cost-effective, and with shorter operative duration and more rapid recovery. It could also achieve a cure rate as high as $98.6 \%$ with less surgical complications, such as postoperative hypocalcemia and recurrent laryngeal nerve injury ${ }^{8-10}$ In our institution, the most commonly used
ISSN 0857-1074 (Print) I eISSN 2308-118x (Online)

Printed in the Philippines

Copyright (C) 2020 by Francisco et al.

Received: May 31, 2019. Accepted: December 9, 2019.

Published online first: May 4, 2020.

https://doi.org/10.15605/jafes.035.01.13
Corresponding author: Danica C. Francisco, MD, FPCP

Fellow-in-training

Section of Endocrinology, Diabetes and Metabolism

The Medical City, Meralco Compound

Ortigas Avenue, Pasig City 1605, Philippines

Tel. No.: +632-8988-1000

E-mail: danica127@yahoo.com

ORCiD: https://orcid.org/0000-0002-2335-6849 
preoperative imaging studies are neck ultrasonography and $99 \mathrm{mTc}$-sestamibi scan. The accuracy of these modalities in locating abnormal parathyroid glands varies among international studies. Generally, in the western countries, neck UTZ is reported to have a sensitivity of 45 to $88 \%$ and a specificity of 94 to $98 \%$. For MIBI, the reported sensitivity is 54 to $70 \%$ and specificity 95 to $100 \% \cdot{ }^{11-13}$ Nevertheless, it should be noted that preoperative localization is primarily done not to influence the decision to operate but to aid in planning the surgical approach by suggesting either the location of a single lesion or increase suspicion for multiglandular disease. ${ }^{14}$ Abnormal parathyroid glands may still be found in diagnosed patients regardless of imaging result, so that a negative imaging study does not preclude parathyroid surgery. A negative result may suggest multiglandular disease or an ectopic parathyroid tumor, which may then indicate the need for more extensive surgical exploration to locate the pathologic gland. A review of a prospective database in a tertiary care center in the United States showed that of those who underwent neck exploration for PHPT, $40 \%$ of the patients with negative results in both UTZ and MIBI had multiglandular disease. The findings provided additional value and importance to preoperative localization studies in surgical planning. ${ }^{15}$

Published literature on parathyroid diseases in the Philippines generally discuss atypical case presentations or management outcomes. The biggest cohort study of Filipino patients described clinical profiles of hemodialysis patients with diabetic kidney disease and secondary hyperparathyroidism. ${ }^{16}$ There is a scarcity of local data assessing the efficiency of imaging modalities in localizing pathologic parathyroid glands. Potential improvement in preoperative planning and techniques remains a challenge. Consequently, this study aims to describe the clinical profiles of Filipino patients with primary hyperparathyroidism who underwent parathyroidectomy and to assess the concordance of commonly utilized preoperative localization imaging (UTZ and MIBI) with surgical histopathologic findings.

\section{METHODOLOGY}

A cross-sectional study was conducted among patients with PHPT who underwent parathyroidectomy at The Medical City from January 2004 to August 2018. The study protocol was approved by the hospital Institutional Review Board. The search terms "hyperparathyroidism," "parathyroidectomy" and "parathyroid surgery" were used at the Medical Records database and yielded a total of 40 hyperparathyroid patients post-parathyroidectomy. The records of all 40 patients were retrieved and reviewed for this study. The subjects were classified based on their clinical history and biochemical test results using the following definitions:

1. primary hyperparathyroidism: above normal intact PTH (iPTH) accompanied by elevated levels of ionized calcium in the absence of end-stage renal disease,

2. secondary hyperparathyroidism: above normal iPTH accompanied by low levels of ionized calcium, and

3. tertiary hyperparathyroidism: above normal iPTH accompanied by elevated levels of ionized calcium in a patient with long-standing end-stage renal disease prior to the diagnosis of hyperparathyroidism.

Filipino patients clinically diagnosed and biochemically confirmed to have PHPT on the basis of elevated ionized calcium and iPTH levels, with neck or thyroid ultrasonography and/or parathyroid scintigraphy as preoperative localization imaging, and with available postoperative histopathology result were eligible for inclusion in the study. Thirty-five subjects were included in the analysis (Figure 1).

Demographic and clinical data were gathered from medical and attending physician records. These included age, gender, symptoms, comorbidities, family history of parathyroid and thyroid disease, risk factors for hyperparathyroidism (lithium intake, thiazide intake, neck radiation exposure), estimated duration of signs and symptoms prior to surgery, time interval from diagnosis

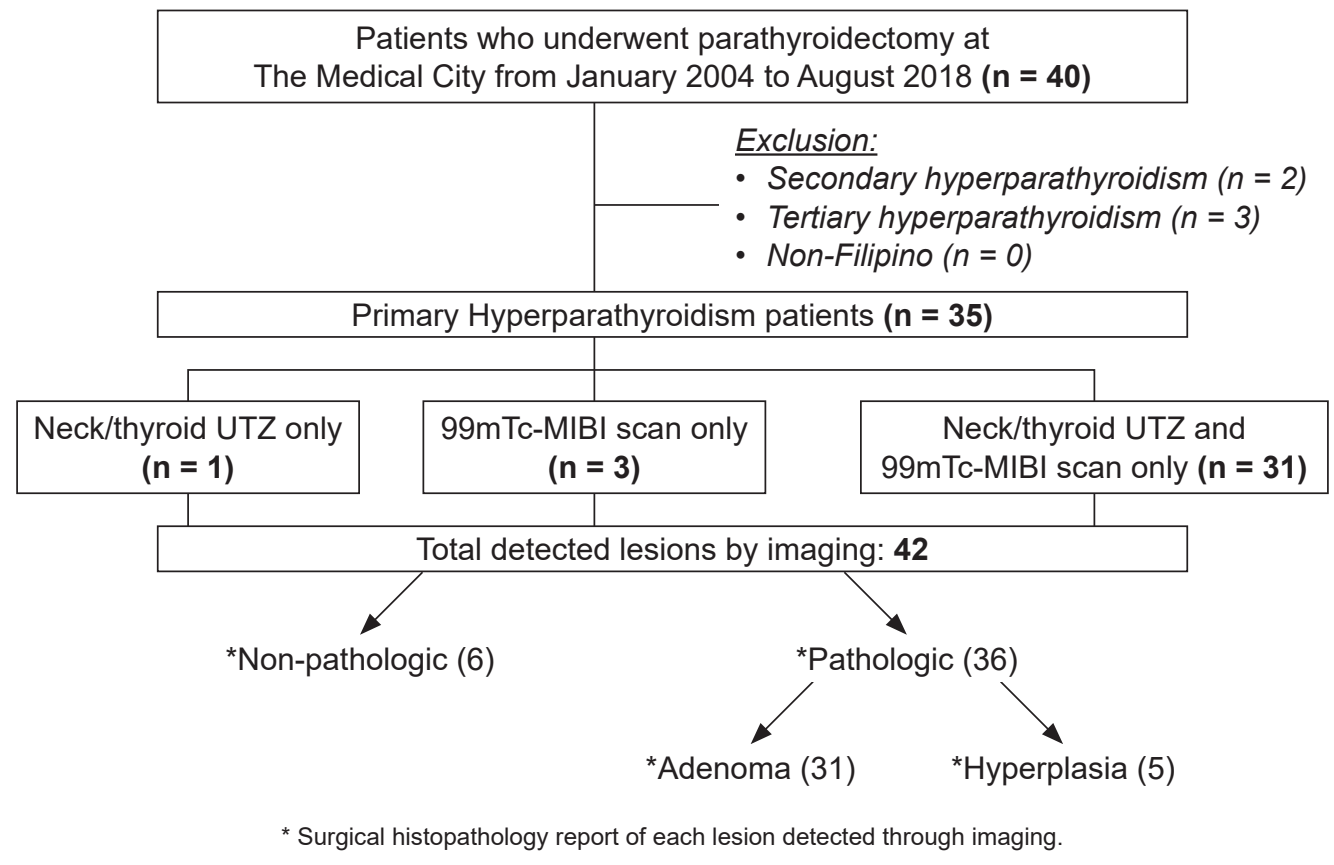

Figure 1. Flow diagram of study patients and imaging findings. 
to surgery, indications for surgery and type of surgery done. Biochemical test results included preoperative ionized calcium, iPTH, serum phosphorus, serum creatinine and eGFR (CKD-EPI equation) and vitamin D.

Asymptomatic PHPT was defined as a diagnosis made by routine laboratory testing without any overt clinical signs or symptoms of the disease. Indications for surgery for these patients were based on the 2014 Guidelines for the Management of Asymptomatic Primary Hyperparathyroidism. ${ }^{17}$ All official imaging results were retrieved from the Radiology and Nuclear Medicine Departments of TMC. The Siemens Acuson S2000 ${ }^{\mathrm{TM}}$ was used for ultrasonography from 2008 until 2018. Seven patients had their UTZ done before 2008 using an older version of the current machine, but with the same frequency and with no significant difference in resolution. TMC radiologists have been using high frequency linear transducers with color Doppler interrogation since 2004, with no change in technique. The results, however, were interpreted by 16 different radiologists through the years. The MIBI scans, on the other hand, were performed with ${ }^{99 \mathrm{~m}} \mathrm{Tc}$ using the single photon emission computed tomography (SPECT) dual-phase technique. A planar technetium 99m-pertechnetate/technetium 99m-MIBI subtraction scintigraphy and tomographic images were acquired after intravenous injection of technetium 99m-MIBI. The MIBI scan reports were read by 12 different nuclear medicine consultants within the years included in this study. With the exception of 3 images that were done outside our institution, all studies were confirmed and signed by a single senior consultant from our Nuclear Medicine Department. These were then compared with the surgical and histopathologic findings acquired from the operative records and the Pathology Department which served as the gold standard. Since distinguishing between the upper and lower gland locations may be difficult due to anatomic variability, imaging results were compared against tumor laterality alone. The imaging characteristics that were gathered included the number and location by laterality of the parathyroid lesion detected. The histopathologic characteristics taken were the number, location, size and histologic type (adenoma, hyperplasia, carcinoma or non-pathologic) of the parathyroid gland.

A positive preoperative imaging test, either by neck UTZ or MIBI scan, is defined as having detected the presence of a parathyroid lesion. Localization was considered correct when the imaging correctly identified the side of the neck in which the histopathologically confirmed abnormal gland was surgically found. The preoperative imaging is said to be concordant if it showed the lesion at the same side of the neck as with the surgical findings, and discordant if the lesion on the imaging is at the opposite side of the neck seen intraoperatively. The degree of agreement between surgical findings and imaging results was analyzed.

Descriptive statistics were used to summarize the general and clinical characteristics of the participants. Frequency and proportion were used for nominal variables, median and range for ordinal variables, and mean and standard deviation for interval/ratio variables. We determined the Kappa statistic to calculate the degree of concordance of the neck UTZ and MIBI localization with the histopathologic localization. The formula for kappa coefficient, $\kappa$, is:

$$
\frac{P_{o}-P_{e}}{1-P_{e}}
$$

where $P_{o}$ is the actual observed agreement and $P_{e}$ is the expected agreement. The expected agreement is the proportion of localizations expected to agree due to chance. Missing variables were neither replaced nor imputed. Stata 15.0 was used for data analysis.

\section{RESULTS}

A total of 35 patients with primary hyperparathyroidism who underwent parathyroidectomy were included in the analysis (Table 1). The mean age was 53 years with a female predominance (63\%). Surgery for PHPT was more frequent in the age groups of 51 to 70 years among females and 41 to 50 years among males. The most common specific manifestations were osteoporosis/osteopenia (51\%) and nephrolithiasis (49\%). Muscle or joint pains $(43 \%)$, constitutional (34\%) and various gastrointestinal symptoms (31\%) were found to be the more common nonspecific presentations. Twenty percent had behavioral changes, with depression and irritability or emotional lability being most commonly observed. Other infrequent nonspecific symptoms included an anterior neck mass, changes in posture and height, and neurologic symptoms such as headache and dizziness. There were $27(77 \%)$ patients

Table 1. Clinical characteristics of patients with primary hyperparathyroidism who underwent parathyroidectomy

\begin{tabular}{lc}
\hline \multicolumn{1}{c}{ Characteristic } & Total \\
$\mathbf{n}=35$ \\
\hline Mean age, year (SD) & $53 \pm 13.48$ \\
\hline Female gender (\%) & $22(62.86)$ \\
\hline Presentation (\%) & \\
Asymptomatic & $3(8.57)$ \\
Specific signs and symptoms & \\
Osteoporosis or osteopenia & $18(51.43)$ \\
Nephrolithiasis and nephrocalcinosis & $17(48.57)$ \\
Bone fracture & $4(11.43)$ \\
Nonspecific signs and symptoms & \\
Constitutional symptoms & \\
Easy fatigability, lethargy or weakness & $12(34.29)$ \\
Weight loss & $6(17.14)$ \\
Gastrointestinal symptoms & $11(31.43)$ \\
Nausea or vomiting & $2(5.71)$ \\
Abdominal pain & $6(17.14)$ \\
Constipation & $3(8.57)$ \\
Anorexia & $1(2.86)$ \\
Pancreatitis & $1(2.86)$ \\
Peptic ulcer or gastroesophageal reflux disease & $4(11.43)$ \\
Muscle or joint pains & $15(42.86)$ \\
Psychiatric or behavioral changes & $7(20)$ \\
Palpitations or chest pain & $6(17.14)$ \\
Others & $10(28.57)$ \\
\hline Medical history & \\
Hypertension & $22(62.86)$ \\
Thyroid disease & $27(77.14)$ \\
Diabetes & $14(40)$ \\
Chronic kidney disease & $12(34.29)$ \\
Stage 1 & $1(8.33)$ \\
Stage 2 & $2(16.67)$ \\
Stage 3 & $8(66.67)$ \\
Stage 4 & $1(8.33)$ \\
Heart or coronary artery disese & $4(11.43)$ \\
Lithium intake & $1(2.86)$ \\
Neck radiation exposure & 0 \\
Thiazide use & $2(5.71)$ \\
Others & $10(28.57)$ \\
\hline Family history & \\
Thyroid disease & $9(25.71)$ \\
Parathyroid disease & $1(2.86)$ \\
\hline a SD, standard deviation & \\
& \\
& \\
&
\end{tabular}


Table 2. Preoperative laboratory profiles

\begin{tabular}{|c|c|c|c|}
\hline & All subjects $(n=35)$ & CKD $^{c}$ subgroup $(n=12)$ & Reference range \\
\hline Ionized calcium, mg/dL & $6.12(5.45-8.44)$ & $6.56(5.48-8.44)$ & $4.6-5.32$ \\
\hline iPTH ${ }^{\mathrm{a}}, \mathrm{pg} / \mathrm{mL}$ & $202.6(69.89-849.4)$ & $261.05(118-849.4)$ & $15-65$ \\
\hline Phosphorus, mg/dL & $2.63(1.95-3.5)$ & $2.59(2.24-2.91)$ & $2.29-4.71$ \\
\hline Vitamin D, ng/mL & $25.8(12.1-42.22)$ & $26.56(12.99-42.22)$ & $>30$ \\
\hline Serum creatinine, $\mathrm{mg} / \mathrm{dL}$ & $1.06(0.48-2.4)$ & $1.49(1.17-2.4)$ & $0.55-1.02$ \\
\hline eGFR ${ }^{b}, \mathrm{~mL} / \mathrm{min} / 1.73 \mathrm{~m}^{2}$ & $66(21-120)$ & $44(21-64.5)$ & $>120$ \\
\hline
\end{tabular}

who had multinodular goiters, 3 of whom had papillary thyroid cancer. Nine patients $(26 \%)$ had reported thyroid disease in the family, while only one had a family history of parathyroid disease.

Preoperatively, the median ionized calcium was elevated (6.12 mg/dL), while median phosphorus was normal (2.63 $\mathrm{mg} / \mathrm{dL}$ ). iPTH levels varied widely from 69.89 to $849.4 \mathrm{pg} /$ $\mathrm{mL}$ (reference value $15-65 \mathrm{pg} / \mathrm{mL}$ ), as observed in the typical biochemical picture of primary hyperparathyroidism

\section{Table 3. Operative and histopathologic profiles}

\begin{tabular}{|c|c|}
\hline Characteristic & $\begin{array}{l}\text { Mean or } \\
\text { frequency }\end{array}$ \\
\hline $\begin{array}{l}\text { Estimated duration of signs and symptoms prior to surgery, } \\
\text { year (range) }\end{array}$ & $2(0.04-13)$ \\
\hline Estimated time from diagnosis to surgery, month (range) & $4(0.25-72)$ \\
\hline $\begin{array}{l}\text { Frequency of surgical indications (\%) } \\
\text { Osteoporosis/osteopenia } \\
\text { Nephrolithiasis } \\
\text { Muscle or joint pains } \\
\text { Age }<50 \text { years } \\
\text { Easy fatigability/lethargy } \\
\text { Gastrointestinal symptoms } \\
\text { eGFR }<60 \mathrm{~mL} / \mathrm{min} / 1.73 \mathrm{~m}^{2} \\
\text { Fracture } \\
\text { Suggestive of cancer }\end{array}$ & $\begin{array}{c}18(51.43) \\
17(48.57) \\
15(42.86) \\
14(40) \\
12(34.29) \\
11(31.43) \\
9(25.71) \\
4(11.43) \\
1(2.86) \\
\end{array}$ \\
\hline $\begin{array}{l}\text { Surgery performed }(\%) \\
\text { Parathyroidectomy only } \\
\text { Total thyroidectomy + parathyroidectomy } \\
\text { Thyroid lobectomy + parathyroidectomy } \\
\text { Subtotal thyroidectomy + parathyroidectomy }\end{array}$ & $\begin{array}{c}15(42.86) \\
9(25.71) \\
8(22.86) \\
3(8.57)\end{array}$ \\
\hline $\begin{array}{l}\text { Largest size of parathyroid lesion per subject }(n=33)(\%) \\
\leq 1 \mathrm{~cm} \\
1.1 \text { to } 2.0 \mathrm{~cm} \\
2.1 \text { to } 3.0 \mathrm{~cm} \\
>3 \mathrm{~cm}\end{array}$ & $\begin{array}{c}7(21.21) \\
15(45.45) \\
8(24.24) \\
3(9.09)\end{array}$ \\
\hline Actual largest size of parathyroid lesion, $\mathrm{cm}\left(\mathrm{SD}^{\mathrm{b}}\right)$ & $1.83(0.92)$ \\
\hline $\begin{array}{l}\text { Type of suspected parathyroid lesions detected through } \\
\text { imaging }(\mathrm{n}=42)(\%) \\
\text { Non-pathologic } \\
\text { Pathologic } \\
\text { Adenoma } \\
\text { Hyperplasia }\end{array}$ & $\begin{array}{c}6(14.29) \\
36(85.7) \\
31(86.1) \\
5(13.9)\end{array}$ \\
\hline
\end{tabular}

(Table 2). None of these patients had longstanding endstage renal disease. Analyzed separately, the patients with chronic kidney disease had elevated iPTH (median $261.05 \mathrm{pg} / \mathrm{mL}$ ), elevated serum ionized calcium (median $6.56 \mathrm{mg} / \mathrm{dL}$ ) and normal phosphorus (median $2.59 \mathrm{mg} /$ $\mathrm{dL})$, consistent with primary hyperparathyroidism. The lone patient with stage 4 CKD had an earlier episode of acute kidney injury due to renal stones months before her parathyroidectomy, and was unable to regain her previous renal function. Approximately $67 \%$ of the CKD patients had chronic hypercalcemia, and the ensuing azotemia was attributed to obstructive uropathy caused by PHPT. The median vitamin $\mathrm{D}$ in this subset of patients with CKD was slightly below normal $(26.56 \mathrm{ng} / \mathrm{mL})$, with only one patient having a level below $20 \mathrm{ng} / \mathrm{mL}$.

The estimated mean duration of signs and symptoms prior to surgery was 2 years, with a wide range from a few weeks to as long as 13 years. The approximate time interval between diagnosis and parathyroid surgery was 4 months (Table 3). The predominant indications for surgery in this population reflected the most frequent clinical manifestations of osteoporosis and nephrolithiasis. Other indications are seen in Table 3. With the exception of one, all patients had multiple indications for surgery at presentation. Eighteen (51\%) subjects had at least 3 indications, while $6(17 \%)$ had 5 or more. There were only $3(9 \%)$ asymptomatic patients in this population. These patients presented with incidental findings of hypercalcemia (more than $1 \mathrm{mg} / \mathrm{dL}$ above the normal limit) and decreased eGFR $\left(<60 \mathrm{ml} / \mathrm{min} / 1.73 \mathrm{~m}^{2}\right)$, serving as their indications for surgery.

Neck UTZ and MIBI was not done in all patients: 32 (91.4\%) had UTZ and 34 (97.1\%) had MIBI. Of the 35 patients, 31 $(88.6 \%)$ had both imaging done leaving only one patient with UTZ alone and 3 patients with MIBI only. Collectively, there was a total of 42 suspected lesions detected by imaging from the 35 subjects. A summary of imaging findings for each of the 42 suspected lesions is seen in Tables 4 and 5 . Single-gland disease was the predominant finding. There

Table 4. Individual preoperative imaging results of each specimen $(n=35)$

\begin{tabular}{|c|c|c|c|c|}
\hline & Non-pathological $(n=6)$ & Adenoma $(n=31)$ & Hyperplasia $(n=5)$ & Total lesions $(n=42)$ \\
\hline \multicolumn{5}{|l|}{ UTZa $(\%)$} \\
\hline Positive & 0 & $18(58.06)$ & 0 & $18(42.86)$ \\
\hline Negative & $3(50)$ & $12(38.71)$ & $4(80)$ & $19(45.24)$ \\
\hline No imaging & $3(50)$ & $1(3.23)$ & $1(20)$ & $5(11.9)$ \\
\hline \multicolumn{5}{|l|}{$\mathrm{MIBI}^{\mathrm{b}}(\%)$} \\
\hline Positive & $6(100)$ & $25(80.65)$ & $5(100)$ & 36 (85.71) \\
\hline Negative & 0 & $4(12.9)$ & 0 & $4(9.52)$ \\
\hline No imaging & 0 & $2(6.45)$ & 0 & $2(4.76)$ \\
\hline
\end{tabular}


Table 5. Combined preoperative imaging results of each specimen $(n=31)$

\begin{tabular}{|c|c|c|c|c|}
\hline & Non-pathological $(n=6)$ & Adenoma $(n=31)$ & Hyperplasia $(n=5)$ & Total lesions $(n=42)$ \\
\hline Positive on both (\%) & 0 & $15(53.57)$ & 0 & $15(42.86)$ \\
\hline Positive UTZ ${ }^{a}$ and Negative $\mathrm{MIBI}^{\mathrm{b}}(\%)$ & 0 & $2(7.14)$ & 0 & $2(5.71)$ \\
\hline Negative UTZ ${ }^{\mathrm{a}}$ and Positive MIBI ${ }^{\mathrm{b}}(\%)$ & $3(100)$ & $9(32.14)$ & $4(100)$ & $16(45.71)$ \\
\hline Negative on both (\%) & 0 & $2(7.14)$ & 0 & $2(5.71)$ \\
\hline
\end{tabular}

were $3(8.6 \%)$ diagnosed to have multiple gland disease after surgery, in whom 2 pathologic parathyroid lesions were confirmed. Through histopathologic examination, the number of true pathologic lesions was 36 out of the 42 detected through imaging. These were composed of 31 adenomas $(86.1 \%)$ and 5 hyperplastic glands $(13.9 \%)$; the remaining 6 suspected lesions through imaging turned out to be non-pathologic. Although MIBI notably detected 6 false positives, it was able to detect all of the hyperplastic glands which UTZ failed to recognize. In addition to this, UTZ had 3 times more false negative results for adenomas compared to MIBI (38.7\% versus $12.9 \%$ ). When both imaging procedures were done as seen in 31 of the subjects, there were 2 adenomas found during surgery that were not seen on both UTZ and MIBI. There was no apparent common characteristic that could explain the negative imaging result. The sizes of the missed adenomas were more than $1 \mathrm{~cm}(1.3$ and $2.6 \mathrm{~cm})$, with associated PTH levels close to 3 times higher than normal (185.5 and $218.4 \mathrm{pg} / \mathrm{mL}$ ). Although both were found in patients with multinodular goiters, there were 20 other adenomas found in patients with nodular goiters that were detected by either or both UTZ and MIBI. Imaging results of the 31 subjects were seen in agreement in 17/35 (48.6\%) of lesions (positive in 15 , negative in 2) and in disagreement in 18/35 (51.4\%) of lesions (UTZ-positive/MIBI-negative in 2, UTZ-negative/ MIBI-positive in 16) including the 3 false positives in MIBI.

A total of 32 confirmed pathological glands was seen among the 31 patients who had both imaging tests performed (Figure 2). MIBI detected a proportionally bigger percentage of the pathologic lesions compared to UTZ (87.5\% versus 53\%). The average lesion size identified on UTZ $(1.95 \mathrm{~cm})$ was comparable to the size detected in MIBI $(1.75 \mathrm{~cm})$. The average PTH levels were $321.44 \mathrm{pg} /$ $\mathrm{mL}$ and $292.27 \mathrm{pg} / \mathrm{mL}$ for UTZ-positive and MIBI-positive lesions, respectively. Although PTH levels for UTZ-positive lesions were higher, PTH may not truly distinguish the 2 groups in this study since the highest $(849.4 \mathrm{pg} / \mathrm{mL})$ and lowest (below $100 \mathrm{pg} / \mathrm{mL}$ ) were detected by both modalities. In terms of localization, whether individual or combined, they had a small range of difference in rate from 93 to $97 \%$ (Figure 2). Comparing with surgical findings, the concordance of UTZ with histopathology in locating lesions was fair (kappa $=0.375)$, while that of MIBI was moderate (kappa=0.535) (Table 6).

Table 6. Concordance in localization between imaging and surgical histopathology findings

\begin{tabular}{|c|c|c|c|}
\hline & Agreement (\%) & Expected agreement (\%) & kappa $^{c}$ \\
\hline UTZa & 54.05 & 26.52 & 0.375 \\
\hline $\mathrm{MIBI}^{\mathrm{b}}$ & 72.50 & 40.88 & 0.535 \\
\hline \multicolumn{4}{|c|}{$\begin{array}{l}\text { a UTZ, neck ultrasound } \\
{ }^{\mathrm{b}} \mathrm{MIBI}, 99 \mathrm{mTC} \text {-sestamibi scan } \\
{ }^{\mathrm{C}} \text { kappa statistic interpretation according to Landis and Koch: } \leq 0 \text {, none; } \\
0-0.20 \text {, poor; } 0.20-0.40 \text {, fair; } 0.40-0.60 \text {, moderate; } 0.60-0.80 \text {, substantial; } \\
0.8-1 \text {, almost perfect; } 1 \text {, perfect }\end{array}$} \\
\hline
\end{tabular}

\section{DISCUSSION}

In the study population, there were more women who underwent parathyroidectomy for PHPT, with a ratio of 2:1, compared to 3 to $4: 1$ in published data. ${ }^{1,18}$ Disease manifestation in males in this study population appeared to be more common at a younger age - at or before the fifth decade of life-in contrast to females who presented with the illness beyond their fifth decade. The most common presentations were bone-related pathology (63\%) and kidney stones $(48.6 \%)$, also seen in published data on Asian populations. In contrast, studies in North America and Europe report primary hyperparathyroidism detected by routine biochemical screening, when complications of overt skeletal and renal abnormalities have not yet occurred. ${ }^{19}$ As a result, the indications for surgery are predominantly asymptomatic PHPT with abnormal biochemical profiles. In these developed countries, overt renal stone disease was noted in less than $20 \%$, while skeletal abnormalities were much less common at $2 \% .^{19,20}$ Gastrointestinal manifestations such as peptic ulcer disease, on the other hand, appear to be similar to the general population at $10 \%{ }^{21}$ In Asian countries, where screening methods are not as regularly done as in the West, clinically apparent disease sequelae are more frequent, as patients tend to seek consult once symptoms are already overt and bothersome. ${ }^{12,22,23}$ In a study of PHPT patients in India, skeletal manifestations $(75.5 \%)$ were reported as the most common presentation similar to our population, followed by renal calculi (40.5\%) and proximal muscle weakness (45.5\%). The mean duration of symptoms was 2.8 years. ${ }^{21}$ Similarly, in Saudi Arabia, skeletal manifestations (45.7\%) and renal stones (15.2\%) were also common, with an average duration of symptoms of 39 months or 3.2 years. ${ }^{22}$ Comparable findings in Thailand showed skeletal symptoms in $66.7 \%$, renal impairment in $15.6 \%$ and mixed symptoms in $86.7 \% .{ }^{23}$ In the Philippines, a retrospective review of 20 post-parathyroidectomy patients with hungry bone syndrome showed renal calculi $(45 \%)$ as the top preoperative presentation, followed by osteoporosis (30\%), parallel to our data. ${ }^{24}$

The mean duration of signs and symptoms prior to surgery was approximately 2 years (ranging from 2 weeks to 13 years), similar to other Asian countries. About $40 \%$ of the subjects underwent surgery within one year of suspected signs and symptoms of the disease, while $31 \%$ remained symptomatic for one to 5 years before undergoing surgery (Table 3). This is likely due to delayed consultations for mild and tolerable symptoms and underestimation of the disease by patients, as exemplified by irregular followup consultations until more severe and debilitating complications are present. Nonetheless, once the diagnosis has been made, half of the patients were able to undergo parathyroidectomy within 6months(Table3).Unfortunately, due to the subjective nature of nonspecific symptomsbody weakness, depression and abdominal pain-together 


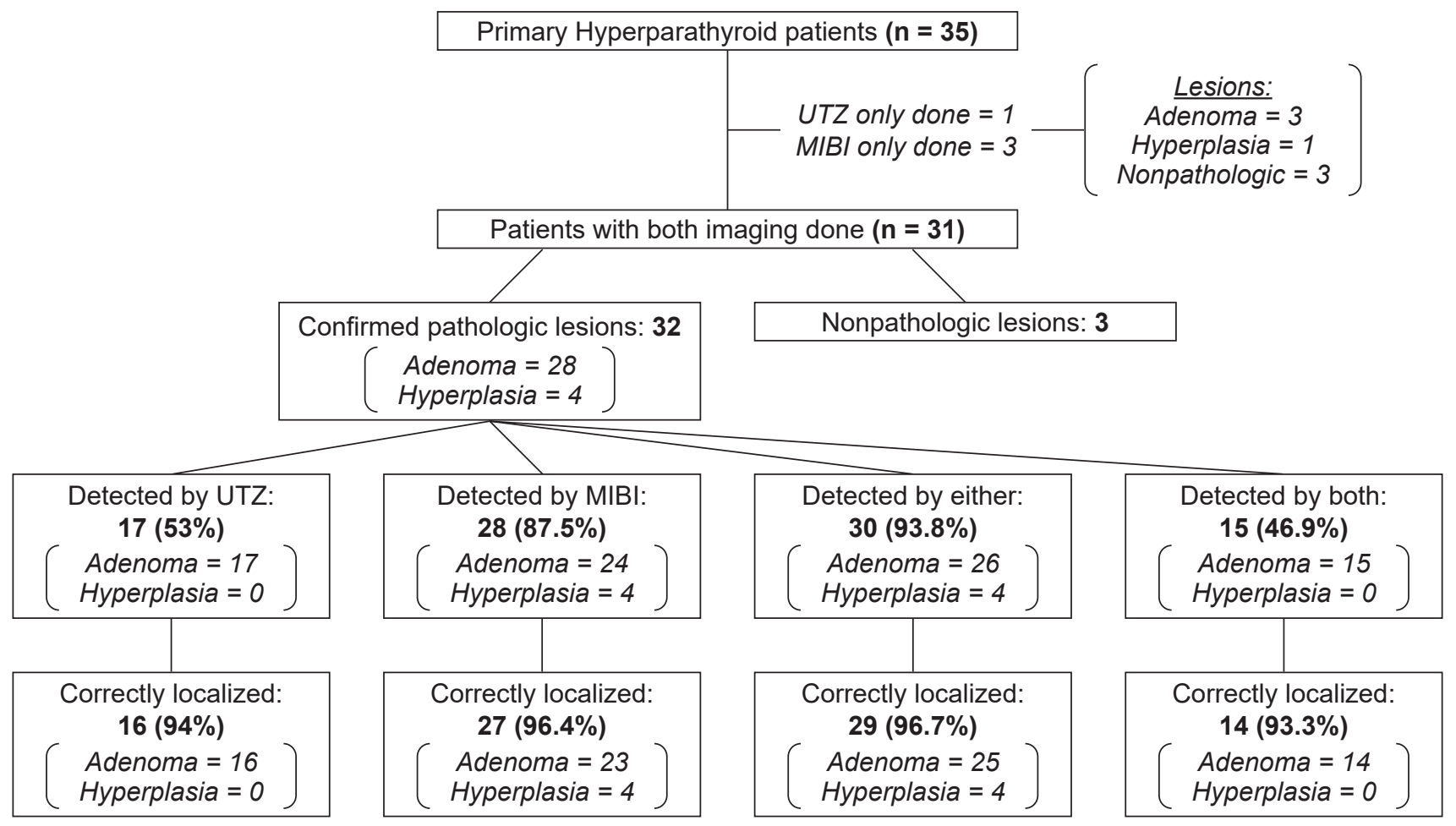

Figure 2. Preoperative imaging detection and localization rates of confirmed pathologic lesions in patients with both UTZ and MIBI.

with the lack of routine biochemical tests including calcium levels, the distinction between asymptomatic and symptomatic primary hyperparathyroidism is not always clear. Therefore, estimation of duration of symptoms relied heavily on persistent and significantly bothersome symptoms reported by the patients.

There was an observed discrepancy between UTZ and MIBI, wherein only $58 \%$ of adenomas were detected by UTZ as opposed to $80 \%$ by MIBI scan (Table 4 ). The low detection rate of UTZ in this study is speculated to be due to several factors, including thyroid nodularity, operator differences in reading abilities and existing incomplete ultrasound protocols. In this study, 26/35 (77\%) of the subjects had multinodular goiters: in those who had both imaging studies, UTZ was able to detect $58 \%$ of lesions while MIBI detected $85 \%$. Similarly, Erbil et al noted a decrease in sensitivity in parathyroid lesion detection from $100 \%$ to $79 \%$ using UTZ in the presence of thyroid nodules. ${ }^{25}$ Additionally, in our institution, there are more operators and readers of parathyroid ultrasonography than parathyroid scintigraphy, which would inevitably result in greater inter-observer variability. Moreover, neck and thyroid UTZ protocols do not routinely search for parathyroid glands, so that these are not always described unless requested by the physician or suggested by the clinical impression. As a result, there are different levels of experience in recognizing parathyroid glands among readers which could greatly affect imaging results. Future studies may consider having a single sonographer and routine inclusion of the parathyroids in thyroid or neck UTZ protocols.

Despite this low detection rate, UTZ remains as one of the most commonly requested imaging tools, as it provides useful information regarding the thyroid gland and its relation to the parathyroids. Evaluating the thyroid for concomitant disease is imperative prior to a primary operation for hyperparathyroidism in order to minimize reoperations. The clinical importance of thyroid nodules lies with the need to exclude thyroid cancer, which occurs in 7 to $15 \%$ depending on demographics and presence of risk factors. ${ }^{26}$ The Philippine Thyroid Diseases Study in 2012 found that the prevalence of nodular goiter was $4.1 \% .^{27}$ Several comparison studies have shown that Filipinos are 2 to 3 times more likely to develop thyroid cancer and are significantly more likely to develop cancer recurrence (25\%) compared to American and Canadian populations $(9.5 \%) .{ }^{28-30}$ It is then essential to include thyroid evaluation in planning for parathyroid surgery especially among Filipinos.

Although UTZ and MIBI together had low positive correspondence at $46.9 \%$ (Figure 2), the use of both and consideration of at least one positive imaging for preoperative localization appears to overcome the inherent limitations of each modality alone and increases detection rate to $93.8 \%$. MIBI aids in interpreting UTZ results, especially in cases of ectopic parathyroid glands, small adenomas, and concomitant thyroid nodules, while UTZ provides detailed anatomic information not seen in nuclear imaging. Analysis of concordance showed higher agreement of MIBI scans $(72.5 \%)$ with surgical location compared to UTZ (54.1\%) (Table 6). However, even at a moderate level of agreement beyond chance $(\kappa=0.535)$ with MIBI, the percentage of reliable data reaches only 35 to $63 \%$-still inadequate for clinical application. In health research, an acceptable inter-rater reliability is at least $80 \%$, since this translates to only $20 \%$ of the data as faulty or erroneous. ${ }^{31}$ The accuracy of MIBI may be dependent on several factors, including the quality of the equipment, technique used, frequency of scans being done 
in an institution and the ability of the reader. The effects of these factors should be investigated and considered in formulating ways to improve MIBI scan precision.

The findings of this study are limited by its retrospective design and small sample size. Variable qualities of history taking and documentation by different interviewers allowed unsystematic, non-uniform and occasionally incomplete sets of data. Missing data per patient, especially laboratory values and maintenance medications, restricts adequate characterization of this population. It would have been ideal to have information on the dose and duration of vitamin D supplementation or other medications such as thiazide diuretics and cinacalcet if there were any given. Additionally, determination of the 24-hour urine calcium levels of these patients would have been able to objectively identify cases of familial hypocalciuric hypercalcemia.

\section{CONCLUSION}

This cohort of Filipino patients at The Medical City demonstrated similar characteristics and manifestations with our neighboring Asian countries. Surgical indication was predominantly due to overtly symptomatic disease as opposed to more asymptomatic surgical patients in western countries. Although UTZ showed very low detection rates, there is still merit in doing both UTZ and MIBI scan for preoperative localization. These are done to increase detection, to assess the thyroid gland by UTZ, and to localize pathologic parathyroid lesions better with the MIBI scan in patients with nodular goiter.

Future studies should investigate the impact of regular calcium screening for hyperparathyroidism to clinical outcomes in the general Philippine population, including whether overt symptoms and end-organ complications may be reduced prior to surgical intervention as seen in western countries. Together with this, prospective investigations on preoperative planning and more comprehensive and uniform clinical examination should be made to adequately confirm our findings and discover modifiable factors that could influence localization imaging reliability.

\section{Acknowledgments}

The authors thank Dr. Irmingarda Gueco (Section of Nephrology) and Drs. Daniel Alonzo and Argelyn Ong (ENT department) of The Medical City for their patient contributions and inputs on the manuscript. The authors also thank Dr. Venus Rosales, 101 Health Research for assistance in the statistical analyses.

\section{Statement of Authorship}

All authors certified fulfillment of ICMJE authorship criteria.

\section{Author Disclosure}

The authors declared no conflict of interest.

\section{Funding Source}

None.

\section{References}

1. Bilezikian JP, Bandeira L, Khan A, Cusano NE. Hyperparathyroidism. Lancet. 2018;391(10116):168-78. PMID: 28923463. https://doi.org/ 10.1016/S0140-6736(17)31430-7.

2. Wermers RA, Khosla S, Atkinson EJ, et al. Incidence of primary hyperparathyroidism in Rochester, Minnesota, 1993-2001: An update on the changing epidemiology of the disease. J Bone Miner Res. 2006;21:171-7. PMID: 16355286. https://doi.org/10.1359/JBMR.050910.

3. Heath H 3rd, Hodgson SF, Kennedy MA. Primary Hyperparathyroidism. Incidence, morbidity and potential economic impact in a community. N Engl J Med. 1980;302(4):189-93. PMID: 7350459. https://doi.org/10.1056/NEJM198001243020402.

4. Abood A, Vestergaard P. Increasing incidence of primary hyperparathyroidism in Denmark. Dan Med J. 2013;60(2): A4567. PMID: 23461985.

5. Stephen AE, Mannstadt M, Hodin RA. Indications for surgical management of hyperparathyroidism: A review. JAMA Surg. 2017;152(9):878-82. PMID: 28658490. https://doi.org/10.1001/jamasurg. 2017.1721.

6. Medas F, Erdas E, Longheu A, et al. Retrospective evaluation of the pre- and postoperative factors influencing the sensitivity of localization studies in primary hyperparathyroidism. Int J Surg. 2016;25:82-7. PMID: 26646659. https://doi.org/10.1016/j.ijsu.2015.11.045.

7. Norman J, Lopez J, Politz D. Abandoning unilateral parathyroidectomy: Why we reversed our position after 15,000 parathyroid operations. J Am Coll Surg. 2012;214(3):260-9. PMID: 22265807. https://doi.org/10.1016/j.jamcollsurg.2011.12.007.

8. Chen H, Sokoll LJ, Udelsman R. Outpatient minimally invasive parathyroidectomy: A combination of sestamibi-SPECT localization, cervical block anesthesia, and intraoperative parathyroid hormone assay. Surgery. 1999;126(6):1016-21. PMID: 10598182. https://doi. org/10.1067/msy.2099.101433.

9. Cohen MS, Finkelstein SE, Brunt LM, et al. Outpatient minimally invasive parathyroidectomy using local/ regional anesthesia: A safe and effective operative approach for selected patients. Surgery. 2005;138(4):681-9. PMID: 16269297. https://doi.org/10.1016/j.surg. 2005.07.016.

10. Udelsman R, Lin Z, Donovan P. The superiority of minimally invasive parathyroidectomy based on 1650 consecutive patients with primary hyperparathyroidism. Ann Surg. 2011;253(3):585-91. PMID: 21183844. https://doi.org/10.1097/SLA.0b013e318208fed9.

11. Purcell GP, Dirbas FM, Jeffrey RB, et al. Parathyroid localization with high-resolution ultrasound and technetium Tc 99m sestamibi. Arch Surg. 1999;134(8):824-30. PMID: 10443804. https://doi.org/10.1001/ archsurg.134.8.824.

12. Șișman P, Gül ÖÖ, Cander S, et al. Sensitivity of localization studies performed by various radiologists in the evaluation of parathyroid lesions. Eur Res J. 2018;4(2):112-7. https://doi.org/10.18621/eurj.308830.

13. Mohammadi A, Moloudi F, Ghasemi-Rad M. Preoperative localization of parathyroid lesion: Diagnostic usefulness of color doppler ultrasonography. Int J Clin Exp Med. 2012;5(1):80-6. PMID: 22328952. PMCID: PMC3272690.

14. Kunstman JW, Kirsch JD, Mahajan A, Udelsman R. Clinical Review: Parathyroid localization and implications for clinical management. J Clin Endocrinol Metab. 2013;98(3):902-12. PMID: 23345096. https://doi.org/10.1210/jc.2012-3168.

15. Elaraj DM, Sippel RS, Lindsay S, et al. Are additional localization studies and referral indicated for patients with primary hyperparathyroidism who have negative sestamibi scan results? Arch Surg. 2010;145(6):578-81. PMID: 20566979. https://doi.org/10.1001/ archsurg.2010.108.

16. Chua CC, Rivero W, Gutierrez MJ, Jasul GV Jr. Prevalence of secondary hyperparathyroidism among outpatient type 2 diabetic patients undergoing hemodialysis in a tertiary hospital. Philipp J Int Med. 2010;48(1):4-8.

17. Bilezikian JP, Brandi ML, Eastell R, et al. Guidelines for the management of asymptomatic primary hyperparathyroidism: Summary statement from the Fourth International Workshop. J Clin Endocrinol Metab. 2014;99(10):3561-9. PMID: 25162665. PMCID: PMC5393490. https://doi.org/10.1210/jc.2014-1413.

18. Gasser RW. Clinical aspects of primary hyperparathyroidism: Clinical manifestations, diagnosis, and therapy. Wien Med Wochenschr. 2013;163(17-18):397-402. PMID: 23990260. https://doi. org/10.1007/s10354-013-0235-z.

19. Bilezikian JP. Primary hyperparathyroidism [Updated 2017 Jan 15]. In: KR Feingold, B Anawalt, A Boyce, et al, eds. Endotext [Internet]. South Dartmouth: MDText.com, Inc.; 2000-. Available from https://www.ncbi.nlm.nih.gov/books/NBK278923.

20. Silverberg SJ, Bilezikian JP. Primary hyperparathyroidism. In: JAH Wass, P Stewart, eds. Oxford Textbook of Endocrinology and Diabetes, 2nd ed. Oxford: Oxford University Press, 2011.

21. Gopal RA, Acharya SV, Bandgar T, Menon PS, Dalvi AN, Shah NS. Clinical profile of primary hyperparathyroidism from western India: A single center experience. J Postgrad Med. 2010;56(2):79-84. PMID: 20622385. https://doi.org/10.4103/0022-3859.65279.

22. Malabu UH, Founda MA. Primary hyperparathyroidism in Saudi Arabia: A review of 46 cases. Med J Malaysia. 2007;62(5):394-7. PMID: 18705474.

23. Prasarttong-Osoth $\mathrm{P}$, Wathanaoran $\mathrm{P}$, Imruetaicharoenchoke $\mathrm{W}$, Rojananin S. Primary hyperparathyroidism: 11-year experience in a single institute in Thailand. Int J Endocrinol. 2012;2012:952426. PMID: 22701120. PMCID: PMC3369527. https://doi.org/10.1155/2012/952426.

24. Padilla-Baraoidan RZM, Capuli-Isidro MJ, Cudal BIB, EmbestroPontillas AA. Hungry bone syndrome (HBS) in patients operated 
for primary hyperparathyroidism (PHPT): A six-year experience Philipp J Otolaryngol Head Neck Surg. 2017;32(2):11-6. https://doi. org/10.32412/pjohns.v32i2.59.

25. Erbil Y, Barbaros U, Yanik BT, et al. Impact of gland morphology and concomitant thyroid nodules on preoperative localization of parathyroid adenomas. Laryngoscope. 2006;116(4):580-5. PMID 16585862. https://doi.org/10.1097/01.MLG.0000203411.53666.AD.

26. Haugen BR, Alexander EK, Bible KC, et al. 2015 American Thyroid Association management guidelines for adult patients with thyroid nodules and differentiated thyroid cancer. Thyroid. 2016;26(1):1133. PMID: 26462967. PMCID: PMC4739132. https://doi.org/10.1089/ thy.2015.0020.

27. Carlos-Raboca J, Jimeno CA, Kho SA, et al. The Philippine Thyroid Diseases Study (PhilTiDeS 1): Prevalence of thyroid disorders among adults in the Philippines. J ASEAN Fed Endocr Soc. 2012;27(1):27-33 https://doi.org/10.15605/jafes.027.01.05.
28. Kus LH, Shah M, Eski S, Walfish PG, Freeman JL. Thyroid cancer outcomes in Filipino patients. Arch Otolaryngol Head Neck Surg. 2010;136(2):138-42. PMID: 20157058. https://doi.org/10.1001/ archoto.2009.206

29. Rossing MA Schwartz SM, Weiss NS. Thyroid cancer incidence in Asian migrants to the United States and their descendants. Cancer Causes Control. 1995;6(5):439-44. PMID: 8547542. https://doi. org/10.1007/bf00052184.

30. Clark JR, Eski SJ, Freeman JL. Risk of malignancy in Filipino with thyroid nodules-a matched pair analysis. Head Neck. 2006;28(5):427-31. PMID: 16287137. https://doi.org/10.1002/hed.20333.

31. McHugh ML. Interrater reliability: The kappa statistic. Biochem Med (Zagreb). 2012;22(3):276-82. PMID: 23092060. PMCID: PMC3900052.

Authors are required to accomplish, sign and submit scanned copies of the JAFES Author Form consisting of: (1) Authorship Certification, that authors contributed substantially to the work, that the manuscript has been read and approved by all authors, and that the requirements for authorship have been met by each author; (2) the Author Declaration, that the article represents original material that is not being considered for publication or has not been published or accepted for publication elsewhere, that the article does not infringe or violate any copyrights or intellectual property rights, and that no references have been made to predatory/ suspected predatory journals; (3) the Author Contribution Disclosure, which lists the specific contributions of authors; and (4) the Author Publishing Agreement which retains author copyright, grants publishing and distribution rights to JAFES, and allows JAFES to apply and enforce an Attribution-Non-Commercial Creative Commons user license. Authors are also required to accomplish, sign, and submit the signed ICMJE form for Disclosure of Potential Conflicts of Interest. For original articles, authors are required to submit a scanned copy of the Ethics Review Approval of their research as well as registration in trial registries as appropriate. For manuscripts reporting data from studies involving animals, authors are required to submit a scanned copy of the Institutional Animal Care and Use Committee approval. For Case Reports or Series, and Images in Endocrinology, consent forms, are required for the publication of information about patients otherwise, appropriate ethical clearance has been obtained from the institutional review board. Articles and any other material published in the JAFES represent the work of the author(s) and should not be construed to reflect the opinions of the Editors or the Publisher.

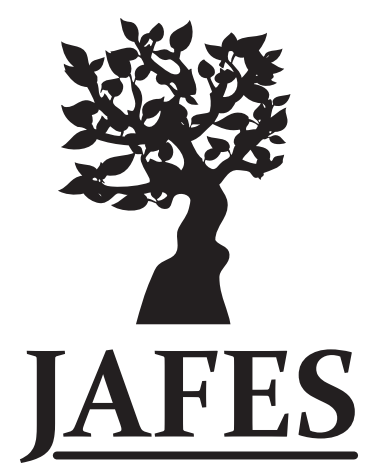

\section{Had an intriguing discussion in Grand Rounds? Share your Clinical Case Seminars at JAFES@Asia.com.}

